\title{
CHARACTERISATION, ANTIBACTERIAL AND ANTICANCER INVESTIGATION OF GREEN SYNTHESIZED SILVER NANOPARTICLES UTILIZING GYMNEMA SYLVERSTRE LEAF BROTH (PODAPATHRI) BY MICROWAVE LIGHT STRATEGY
}

\author{
K. Chandra Rekha, Gugulothu. Yaku and U. Umesh Kumar ${ }^{\bowtie}$ \\ Dept. of Chemistry, Osmania University, Hyderabad, Telangana (state), India 500007 \\ ${ }^{\square}$ Corresponding Author: utkoor@gmail.com
}

\begin{abstract}
The AgNps are synthesized by green strategy using GMMS plant leaf extract (podapathri plant leaves extract). By excretion of microwave irradiation method, the GMMS plant leaf extract which can act as reducing and stabilizing agent. The development of $\mathrm{Ag}$ Nanoparticles was primarily confirmed by altering the color from colorless to yellow. The synthesized Ag Nanoparticles are showing positive antibacterial activity against Stayphylococusaureus, Klebsiella pneumonia, Basillussubtilisand Escherichia coli bacteria were contemplated. The synthesized AgNps divulge virtual anticancer activity on HeLa cells (A549). The particles are very much isolated from one another and did not display any accumulation; this shows the powerful covering nature of GMMS plant leaf extrication (the Podapathri plant leaves separate). Further incorporated AgNps thoroughly characterized by Ultraviolet visible spectra, Fourier Transferred infrared spectra (FT-IR), X-Ray diffraction spectroscopy (XRD), Scanning electron microscopy (SEM), Energy dispersive X-ay investigation (EDS), Transmission electron microscopy (TEM) and Dynamic light dispersing assessment (DLS). The crystalline shape of Ag Nanoparticles is clear from XRD examines. The shape and size of the blended Ag Nanoparticles were examined by TEM studies, The Ag Nanoparticles Size appropriation scatter and the normal size of Ag NPs were discovered to be $18 \pm 2 \mathrm{~nm}$ in size.

Keywords: Green Synthesis, Ag Nanoparticles, GMMS (Gymnema Sylvestre) Plant Leaf Extract, Antibacterial, Anticancer Activity.
\end{abstract}

RASĀYANJ. Chem., Vol. 14, No.3, 2021

\section{INTRODUCTION}

In the past decade, nanoparticles played an important role in philosophical knowledge and automation because of their particular shape, size, trademark properties and extensive scope of possible applications. ${ }^{1}$ Metal nanoparticles having significant electronic, ${ }^{2}$ substance and optical Properties. ${ }^{3}$ In the midst of the few metal nanoparticles, Ag Nanoparticles have huge consideration of science due to their Individual properties such as peasant surface Plasmon resonance (SPR). The noble metal NPs such as Ag has a vital job in biological and medicinal Area. ${ }^{4}$ AgNps are having a huge scope of uses in various fields such as sensor technology, ${ }^{5}$ medical, industrial, thermal, optical, electrical, biological, and food processing method. ${ }^{6}$ There are different strategies for the synthesis of AgNps, such as chemical reduction, biological Reduction photo-induced reduction and green methods. ${ }^{7}$ Among all these green syntheses is the significant and most utilized method for the synthesis of metal nanoparticles, a green synthesis is a novel approach and an alternative to other chemical methods, and it is the most demanding thing for controlling the systems and processes. ${ }^{8}$ Since it is a rapid, non-toxic, renewable and Eco-Friendly method (without using any harsh conditions). ${ }^{9}$

Plant material containing Biomolecules is reasonable for a steady and eco-accommodating combination of Ag nanoparticles, in this green, synthetic procedure, the GMMS leaf plant separate is utilized as a reducing and stabilizing agent for the reduction of silver ions into Ag stable NPs. ${ }^{10}$ Gymnema Sylvestre is an enduring woody plant local to tropical Asia, China, the Arabian Peninsula, Africa, and Australia. ${ }^{11,12}$ It 
has been utilized in Ayurveda medication. The normal name is Gymnema, Australian cow plant, and Periploca of the forested areas. This signifies "sugar destroyer". Today Gymnema is utilized for diabetes (hypoglycemia), metabolic condition, weight loss, and Hack. ${ }^{13}$ It is additionally utilized for intestinal sickness and snake chomp antitoxin, stomach-related energizer, purgative, hunger suppressant, and diuretic. ${ }^{14}$ The antibacterial movement of integrated Ag nanoparticles is assessed, on $\mathrm{G}+\mathrm{ve}$ and $\mathrm{G}-\mathrm{ve}$ bacteria. ${ }^{15}$ The synthesized AgNPs show positive-anticancer action on the cellular breakdown in the lungs cell line (A549), was studied in the agar well dispersion Method. ${ }^{16}$ The optical and physicochemical properties of integrated AgNPs are thoroughly analyzed by different characterization procedures, such as UV-Vi's, FTIR, XRD, SEM-EDX, and TEM microscopic techniques.

\section{EXPERIMENTAL}

\section{Materials and Method.}

$\mathrm{AgNO}_{3}$ was bought from Sigma-Aldrich for a reliable grade of purity without further purification. And the GMMS plant leaf extract (Gymnema Sylvestre podapathri plant) which consists of higher medicinal values. These plants are collected from the botanical garden of Osmania University Hyderabad.

\section{Preparation of GMMS Plant Leaf Extract}

The dissolvable utilized was Nano unadulterated water gotten from a Millipore water cleansing framework for the synthesis of Ag nanoparticles. Almost 10gr of GMMS plant leaves are cut into little pieces and dried under daylight and powdered. And 10gr of leaf powder were taken with $250 \mathrm{ml}$ of the Erlenmeyer jar containing $100 \mathrm{ml}$ of Millipore $\mathrm{H}_{2} \mathrm{O}$ and bubbled at $60^{\circ} \mathrm{c}$ for $45 \mathrm{~min}$ to facilitate the advancement of watery concentrate. The shaped concentrate was separated by the Whatman No.1 channel Paper to get the clear arrangement. Likewise, the cleared GMMS remove Put away under cool conditions for additional examination.

\section{Synthesis of Silver Nanoparticles}

GMMS plant leaf extricates (Gymnema Sylvestre, podapathri plant) arrangement (10mL) was blended with silver nitrate $(5 \mathrm{~mL})$ arrangement of grouped fixations and the combination was exposed to microwave light for $60 \mathrm{sec}$ at $450 \mathrm{~W}$ power. The rise of yellow tinge, essentially adjusts the advancement of silver nanoparticles after the turn of events, the shaped silver nanoparticles were centrifuged and were re-washed with Millipore water to eliminate any un-responsive atoms from the framed Final result of silver nanoparticles.

\section{General Procedure for Antibacterial Activity Test}

The antibacterial examination was done by utilizing the agar well dissemination strategy to explore the bacterial action test. Ag nanoparticles are taken into various volumes such as $25,50,75$ and $100 \mu 1$ separately by dissolving them in DMSO for MIC measure. The counter bacterial movement of the Ag nanoparticles was explored According to the MIC esteem strategy. In this investigation, we have chosen (two $\mathrm{G}+\mathrm{ve}$ and $\mathrm{G}-\mathrm{ve}$ ) bacterial microbes. (a) Stayphylococus aureus zones $(\mathrm{G}+\mathrm{ve})$, (b) E-coli (G -ve) (c) K-pneumonia, (G-ve) (d) Bacillus subtilis $(\mathrm{G}+\mathrm{ve})$ bacterial microorganisms were utilized in this examination.

\section{General Procedure for Anticancer Activity Test}

Cell suitability was surveyed by the MTT studies with 3 autonomous analyses with 6 convergences of mixes in sets of three. Cells were synthetic and play out the tryphan blue measure to know achievable cells in the cell suspension. Cells were checked by hemocytometer and developed at a thickness of 5.0 X $10^{3}$ cells/well in $100 \mu 1$ media in 96 well plate culture medium and agonized for the present at $37^{\circ} \mathrm{C}$. In the wake of incubating, take off the old media and incorporate new media $100 \mu 1$ with different combinations of test blends in addressing wells With 96 plates after $48 \mathrm{hrs}$. Discard the medicine course of action and incorporate the new specialist with an MTT plan $(0.5 \mathrm{mg} / \mathrm{mL}-1)$ was transferred to each well and the plates were incubated at $37^{\circ} \mathrm{C}$ for $3 \mathrm{hrs}$. Toward the end of brooding time, the hastens are shaped account of the Decrease of the MTT salt to chromophoreformazan gems by the phones with metabolically dynamic mitochondria. The optical thickness of dissolvable gems in dimethyl sulfoxides was estimated at 
RASĀYAN J. Chem.

Vol. 14 | No. 3 |2031-2039| July - September | 2021

$570 \mathrm{~nm}$ on a miniature plate per user. The rate development hindrance was Determined utilizing the accompanying recipe.

\section{Detection Methods \\ Optimization and Characterization of GMMS Plant Leaf Extract Synthesized Silver Nanoparticles UV-Visible Analysis of AgNPs}

The yellow color was showing up by the expansion of GMMS plant leaf extricates with silver nitrate arrangement by treating with microwave illumination. Thus, it is essential to affirm that the arrangement of Ag nanoparticles. ${ }^{17}$ The UV, visible spectroscopy (SPR) tops retention Frequency assimilated at 440nm Fig.-1a, it is related to Ag nanoparticles. ${ }^{18}$ What's more, the pinnacles were expanded with expanding the grouping of silver nitrate arrangement, up to the greatest concentration of silver nitrate arrangement. After that if, increment in the convergence of silver Nitrate arrangement, there is no adjustment in UV-visible spectra because there is no accessibility of polyphenols, which are available in GMMS plant leaf separate. ${ }^{19}$ The most extreme polyphenols are used by silver nitrate arrangement. Moreover, the formed silver Nanoparticles by taking an alternate level of GMMS plant leaf separate (1 to 7\%) with a consistent convergence of $\mathrm{AgNO}_{3}(7 \mathrm{mM})$ conc. GMMS leaf stock expands SPR tops additionally increments with the greatest level of the GMMS leaf stock thereafter no change in SPR tops because the grouping of $\mathrm{AgNO}_{3}(7 \mathrm{mM})$ most extreme used by plant extricate Fig.-1b.
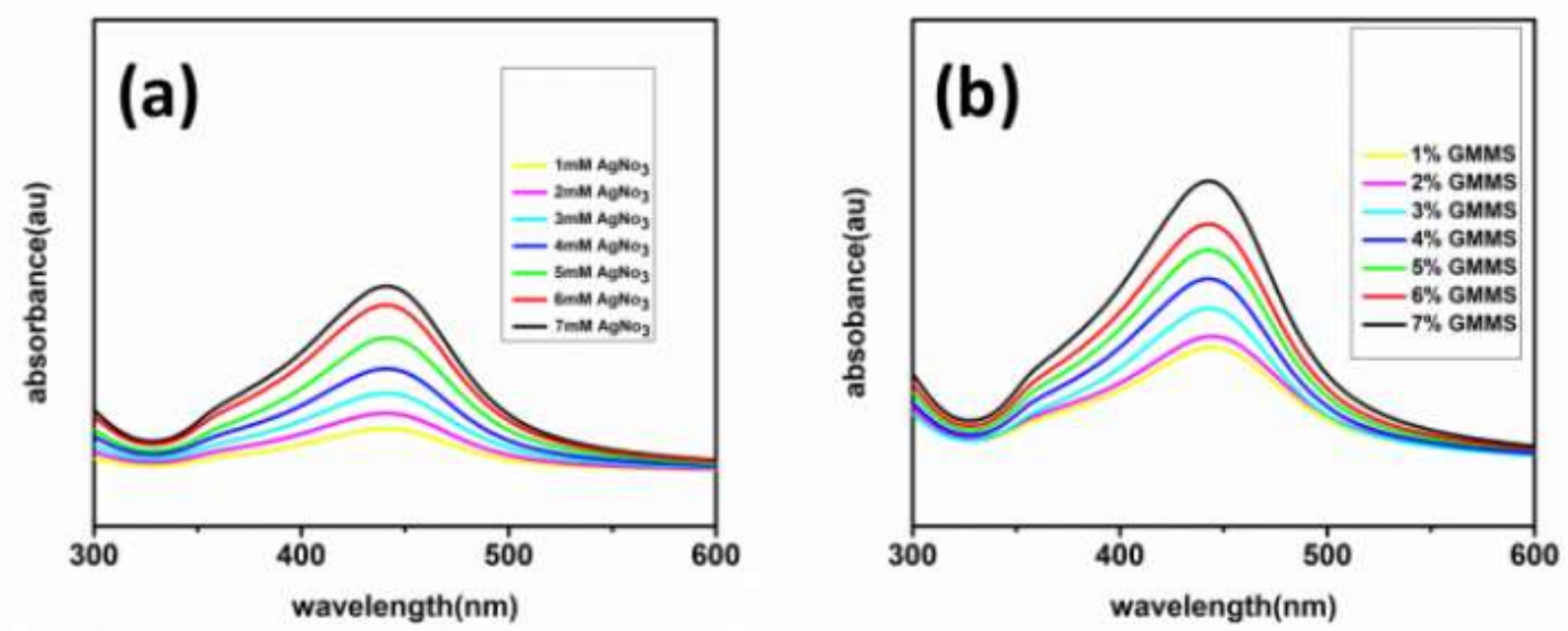

Fig.-1: The Ultraviolet Spectroscopy of Ag NPs (a) Different Concentrations of $\mathrm{AgNO}_{3}$, (b) Different Percentage of GMMS Plant Leaf Extract.

\section{FTIR Analysis of Silver Nanoparticles}

GMMS plant leaf extricates silver nanoparticles by the difference in the inside valuable functional group and GMMS plant leaf removes are filling in as covering/lessening administrator capably without including any external utilitarian get-together. ${ }^{20}$ Fourier Transform Infrared Spectroscopy (FTIR) was recorded to give proof of the change of useful gatherings, GMMS leaf remove related to the decline of $\mathrm{AgNO}_{3}$ and the covering of thusly formed silver nanoparticles Fig.-2. The FTIR spectra of GMMS plant leaf extricate, eliminate shown expanded Vibrations at 3380, 2827, 1737, 1338 and $1010^{\mathrm{cm}-1}$. And GMMS leaf separate secured silver nanoparticles shows broadband frequencies at 3340, 2953, 1716, 1612, 1340, $1030^{\mathrm{cm}-1}$. The wide top at around $3380^{\mathrm{cm}-1}$ identifies with the $\mathrm{O}-\mathrm{H}$ expanding vibrations of polyphenols. The Top at around $2827^{\mathrm{cm}-1}$ identifies with $\mathrm{C}-\mathrm{H}$ broadens and the strong top at around $1737^{\mathrm{cm}-1}$ can be selected to the carbonyl expanding. Further, the tops at around $1050^{\mathrm{cm}-1}$ can be credited to the $\mathrm{C}-\mathrm{O}$ expanding. FTIR spectra of GMMS plant leaf extricate, eliminate spread silver nanoparticles Presented some away from that of GMMS leaf separate alone. ${ }^{21}$ Most importantly the intensity of $\mathrm{O}-\mathrm{H}$ expanding vibrations is decreasing and the power of carbonyl broadening was an addition, which recommends that the hydroxyl bundles are oxidized to carbonyl groups. This maybe a result of the reduction of $\mathrm{Ag}^{+}$ particles by the hydroxyl groups of polyphenol blends and simultaneously phenolic bundles experience oxidation. 


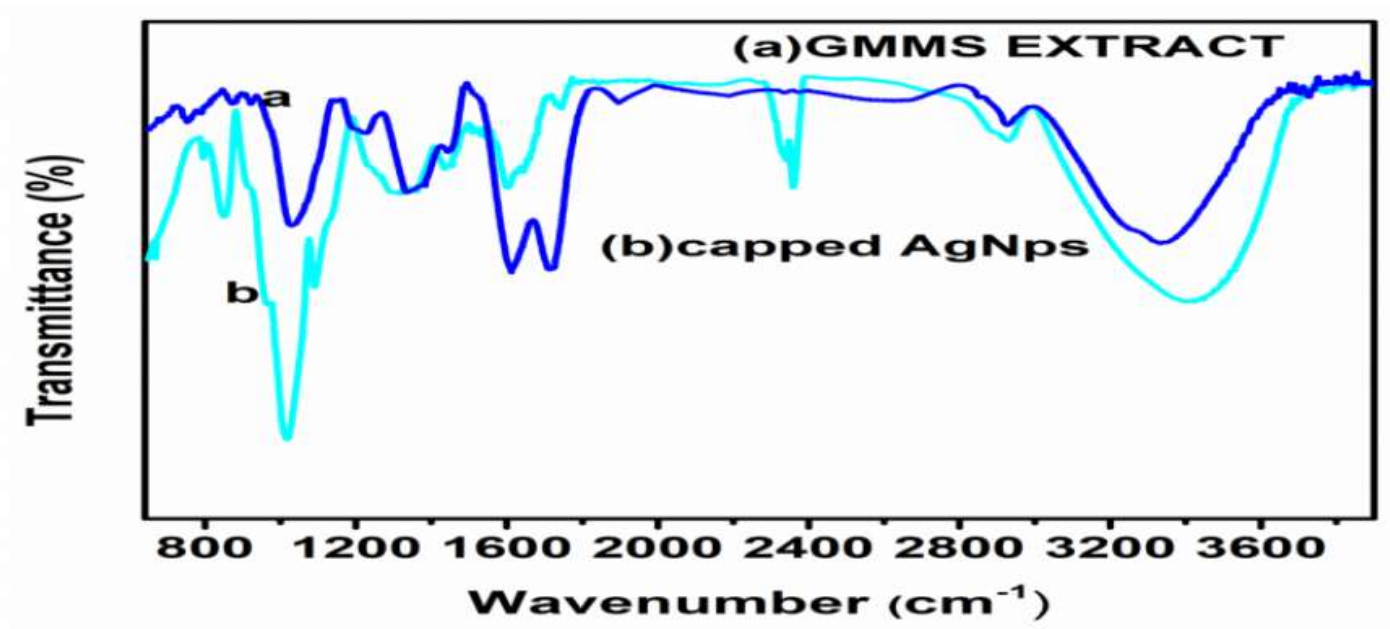

Fig.-2: FTIR Spectra of GMMS and GMMS capped Silver Nanoparticles

\section{X-ray Diffraction (XRD) Analysis of Silver Nanoparticles}

It has been seen that the XRD designs are gotten by silver nanoparticles, integrated by utilizing GMMS plant leaf extricate Fig.-3. Plainly shows four well-defined trademark tops at dispersing points (2 $\theta$ ) of $38.18,45.37,64.16,77.48$ relating to the (111), (200), (220), and (311) arrangements of Cross-section planes, which may be filed as the band for face-focused cubic (FCC) precious stone structure of Ag nanoparticles. ${ }^{22}$ Sets of grid planes are observed at the diffraction top in $38.18^{\circ}$ had sharp and solid pinnacle force demonstrating the particular direction of silver gem along the (111) plane. Also, these are framed from the $\mathrm{Ag}^{0}$ particles and GMMS plant leaf removal, thus it is affirmed that the development of Ag nanoparticles is crystal in nature as per XRD example and TEM examination.

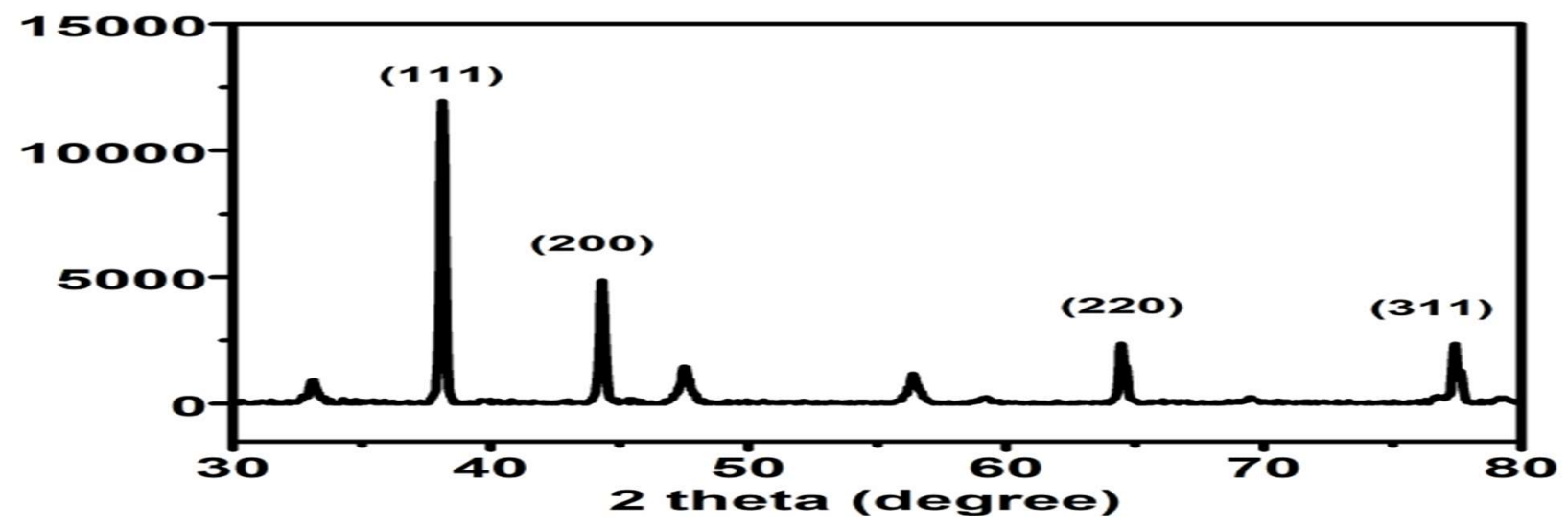

Fig.-3: XRD Pattern of formed Ag Nanoparticles

\section{SEM Images of Silver Nanoparticles}

SEM procedure was utilized to envision the size and state of silver nanoparticles. SEM pictures were gotten from $7 \%$ of GMMS plant leaf extricate with $7 \mathrm{mM} \mathrm{AgNO}_{3}$ solution. The SEM (ZEISS) utilized SEM matrices, which were set up by putting a limited quantity of the test compound on a Copper-covered lattice and drying under the light Fig.-4a. ${ }^{23}$ The arrangement of silver nanoparticles just as their morphological Dimensions in the SEM study showed that the normal size was from $18 \pm 2 \mathrm{~nm}$. In between molecule separation, the states of the silver nanoparticles end up being Circular the SEM picture introduced the $\mathrm{Ag}$ nanoparticles with roughly $20 \mathrm{~nm}$ in size, with almost round fit as a fiddle. EDX examination of Ag nanoparticles exhibited a solid very much characterized silver signal at the $10 \mathrm{KeV}$ alongside powerless carbon, oxygen and nitrogen tops, With the last more fragile signals likely speaking to surface biomolecule covering structures beginning from the leaf separates Fig. $-4 \mathrm{~b}$. 
RASĀYAN J. Chem.

Vol. 14 | No. 3 |2031-2039| July - September | 2021

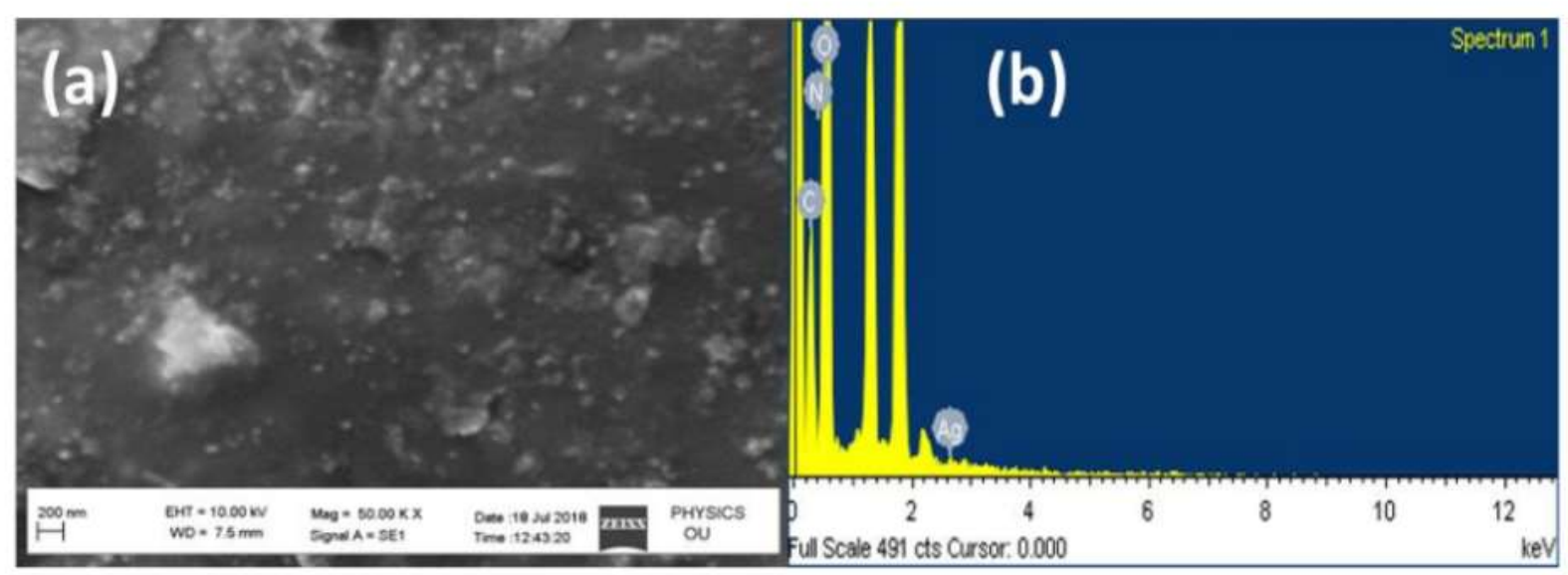

\section{TEM Analysis}

Fig.-4: SEM image of (a) GMMS capped Ag NPs (b) EDX pattern.

Colossal standard of TEM pictures of green figured out GMMS plant leaf separately ensured about Ag nanoparticles using $7 \mathrm{mM}$ silver nitrate and 7\%, GMMS plant leaf extricate under microwave light for $60 \mathrm{sec}$ and at $1000 \mathrm{~W}$ power. Are showed up in Fig.-5a. TEM assessment was Done in examining the molecular size and condition of the Ag nanoparticles, which are joined by using GMMS plant leaf separate free. ${ }^{24}$ TEM evaluation shows that the size and condition of the Ag nanoparticles go from 18 to $20 \mathrm{~nm}$. This evaluation additionally suggests that the blended GMMS plant leaf extricate, take out ensured about Ag nanoparticles are circuitous alive, well and the ordinary size of the Ag nanoparticles is $18 \pm 2 \mathrm{~nm}$ in size. The picked region electron diffraction (SAED) plan shows polycrystalline diffraction rings Fig.$5 \mathrm{~b}$, showing these NPs are clear in Nature. These rings can be credited to the XRD diffractions are the (111), (200), (220), and (311) planes of FCC metallic silver NPs.
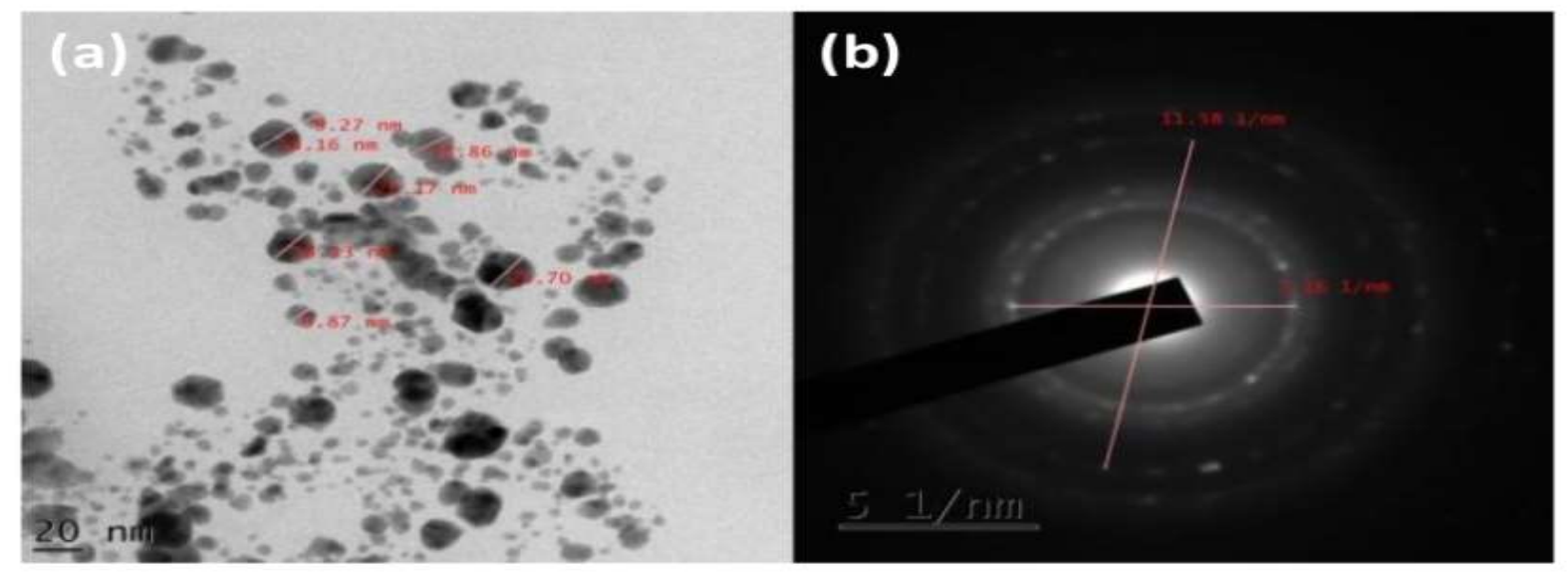

Fig.-5:(a) TEM Images of GMMS capped Silver Nanoparticles at $20 \mathrm{~nm}$, (b) and Selective Electron Diffraction Pattern of Silver Nanoparticles

\section{Antibacterial Activity}

\section{RESULTS AND DISCUSSION}

The disk diffusion method was set up by transferring fluid Nutrient agar in Petri disk and kept it to solidify. From there on, $100 \mu \mathrm{l}$ of inoculums, generally $1.5 \times 10^{8}$ cells $/ \mathrm{ml}$ was developed to the warm fluid agar and transferring outwardly of the solidified Agar. This was permitted to set and Openings of $5 \mathrm{~mm}$ length were prepared into the agar using sterile pipettes. A proportion of $5 \mathrm{mg} / \mathrm{ml} \mathrm{load} \mathrm{of} \mathrm{tests} \mathrm{was} \mathrm{made}$ for every model by solubilizing in $1 \mathrm{ml}$ of $10 \%$ DMSO. $100 \mu \mathrm{L}$ of the stock concentrate was a pipette onto the openings to give a gathering of $0.5 \mathrm{mg}$ per opening. 


\section{Antibacterial Activity of Synthesized Silver Nanoparticles}

The antibacterial action of GMMS plant leaf removes covered Ag nanoparticles are reacted with (a) Staphylococcus aureus (G+ve) Fig.-6a, whose zone of hindrances are (1.2), (1.3), (1.2), (1.1) cm (b) Escherichia coli (G-ve) Fig.-6b, whose zone of restraints are (1.0), (1.1), (1.0), (1.2) cm, (c) Klebisellapneumoniae (G-ve) Fig.-6c, whose zone of hindrances are (1.0), (1.1), (1.2), (1.2), (d) Bacillus subtilis(G+ve) Fig.-6d whose zone of Inhibitions are (1.2), (1.3), (1.2), (1.2) $\mathrm{cm}^{25}$ The zone of the hindrance of Ag nanoparticles for the microorganisms demonstrates the positive antibacterial movement against Staphylococcus aureus, Escherichia coli, Klebsiella pneumonia, and Bacillus subtilis. The antibacterial action results propose that Ag nanoparticles synthesized from GMMS plant leaf extract show the successful antibacterial action against gram-positive than in Gram-negative microorganisms.

Performing Assay for Minimum Inhibitory Concentration of Given Samples (MIC).

$\mathrm{Ag}$ nanoparticle test arrangements examined above were checked for their base inhibitory Focus stacking $25,50,75$, and $100 \mu 1$ of tests in each well of a similar plate separately.

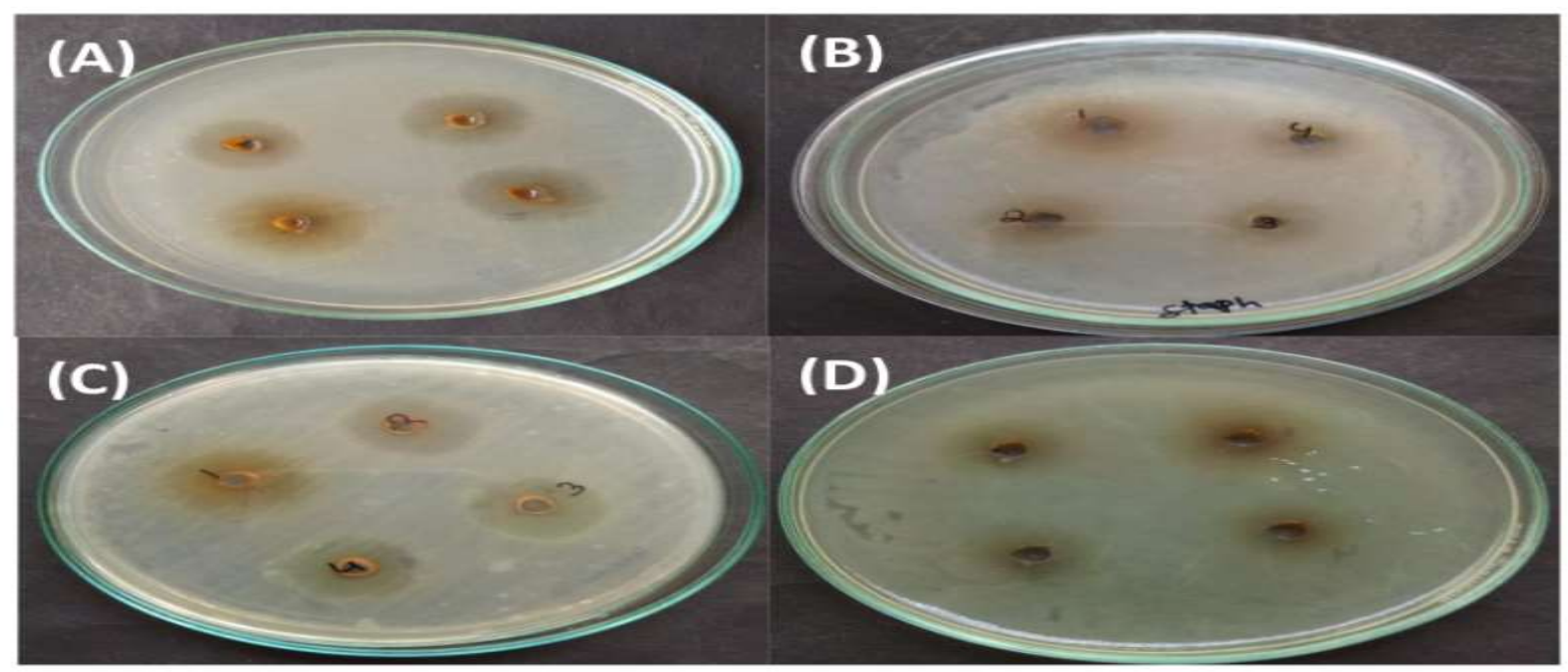

Fig.-6: Antibacterial Activity of GMMS leaf extract capped Ag nanoparticles (a) Stayphylococusarious (b) E-coli (c) KlebisellaNeumonia (d) Basillussubtilis

Table-1: Antibacterial Activity of synthesized Silver Nanoparticles

\begin{tabular}{c|c|c|c|c|c}
\hline \multirow{2}{*}{ S. No. } & & \multicolumn{4}{|c}{ Volume of Sample } \\
\cline { 3 - 6 } & Name of Pathogens & $25 \mu \mathrm{l}$ & $50 \mu \mathrm{l}$ & $75 \mu \mathrm{l}$ & $100 \mu \mathrm{l}$ \\
\hline 1 & Staphylococcus $(\mathrm{G}+\mathrm{ve})$ & 1.2 & 1.3 & 1.2 & 1.2 \\
\hline 2 & E-coli $(G-v e)$ & 1.0 & 1.1 & 1.0 & 1.2 \\
\hline 3 & Klebsiella $(G-v e)$ & 1.0 & 1.1 & 1.2 & 1.1 \\
\hline 4 & Bacillus $(\mathrm{G}+\mathrm{ve})$ & 1.2 & 1.3 & 1.2 & 1.2 \\
\hline
\end{tabular}

\section{Anticancer Activity of Synthesized Silver Nanoparticles}

Calculation of cell feasibility and, extension shapes the justification different in vitro examines of a cell populace's reaction to outside components. The MTT Cell Proliferation studies quantify the cell multiplication rate and then again when metabolic functions lead to Necrobiosis or putrefaction, the decrease in cell practicality.

\section{Anticancer Studies}

The anticancer exercises of GMMS plant leaf removal of synthesized AgNPs, on the cervical cell line $\left(\mathrm{IC}_{50}\right)$ were examined utilizing MTT measure. The morphological changes of cervical cell line $\mathrm{IC}_{50}$, on the expansion of various convergence tests, were recorded utilizing a Cells are Checked by hemocytometer and cultivated at a thickness of $5.0 \times 10^{3}$ cells/well in $100 \mu$ media in 96 well plate 
RASĀYAN J. Chem.

Vol. 14 | No. 3 |2031-2039| July - September | 2021

culture medium and hatched for the time being at $37^{\circ} \mathrm{C}$. The adjustments in the morphology of the cells, for example, adjusting or contracting of cells at the changing of degrees are noticeable in the pictures and it is an away from cytotoxicity. The orchestrated $\mathrm{Ag}$ nanoparticles show huge cytotoxicity against cervical cell line $\mathrm{IC}_{50}$ at various focuses $(5-100 \mu \mathrm{g} / \mathrm{ml})$ than the GMMS leaf separate. Cell death occurred at $100 \mu \mathrm{g} / \mathrm{ml}$ concentration of $\mathrm{Ag}$ nanoparticles is practically $49.44 \%$. The cervical cell line $\mathrm{IC}_{50}$ shows the diminishing level of cell practicality with an expanding percentage of leaf remove and nanoparticles arrangements. Be that as it may, the level of diminishing is higher on account of nanoparticle arrangements ${ }^{26}$. The convergence tests that were needed for half of the restraint $\left(\mathrm{IC}_{50}\right)$ were determined. The $\mathrm{IC}_{50}$ esteems for GMMS plant Leaf separate, Ag nanoparticles, individually are $49.44 \mu \mathrm{g} / \mathrm{mL}$; the high cytotoxic impact of NPs is because of their high fascination towards the organic macromolecules and easy porousness to the cell hindrances. A few examinations revealed that nanoparticles cause cytotoxicity utilizing responsive oxygen species. It does harm the cell segment by intracellular oxidative pressure lastly prompts demise. In our investigation cervical cell line treated with Ag nanoparticles shows a huge enemy of malignant growth action and should make a significant imprint in disease treatment.

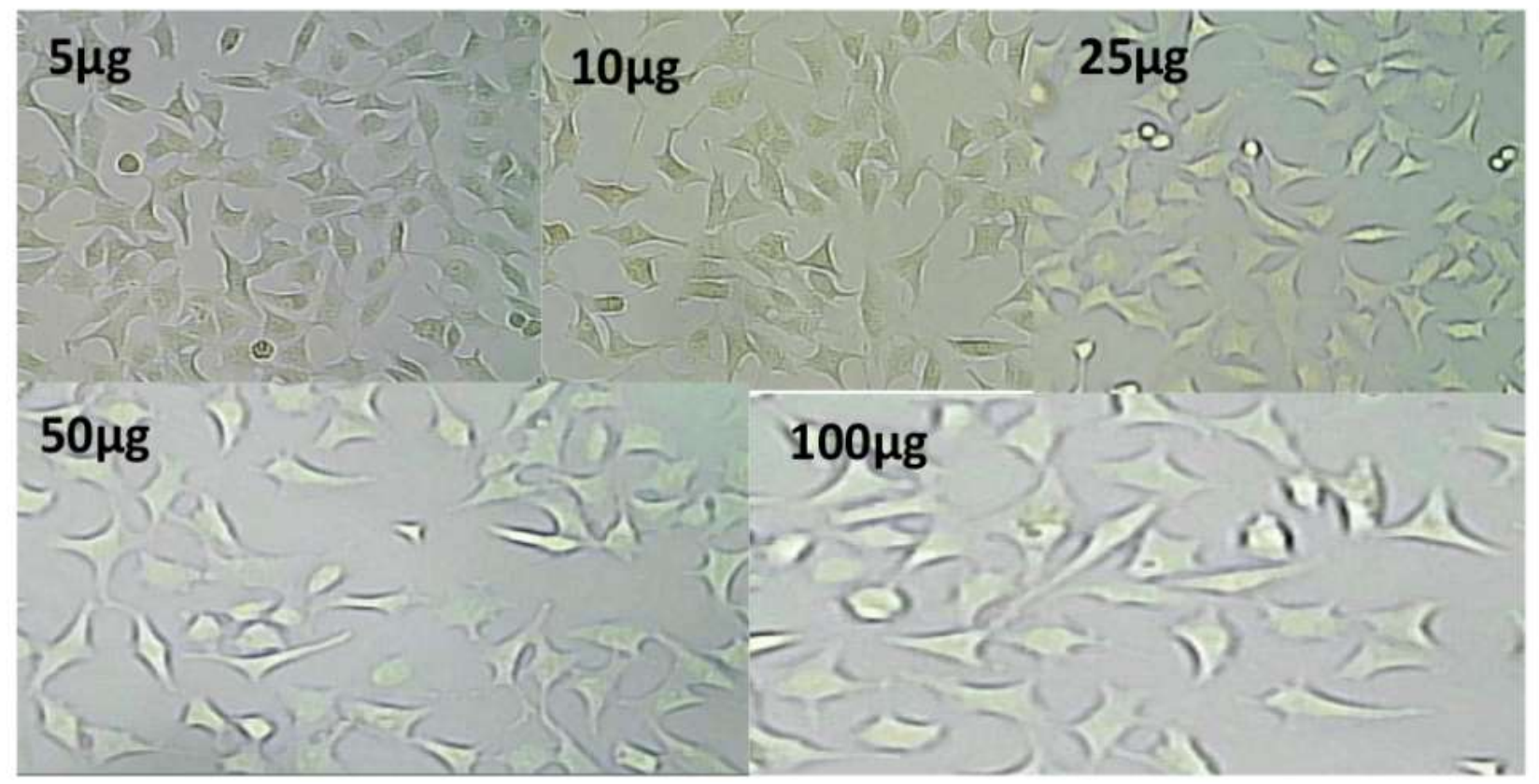

Fig.-7: To Study the Anticancer Activity Test Compounds in-vitro by MTT Analysis.

Tested with HeLa cells shows the $\mathrm{IC}_{50}$ values are as follows in the table provided.

\begin{tabular}{c|c|c}
\hline \multirow{2}{*}{ S. No. } & Sample Name & $\mathrm{IC}_{50}(\mu \mathrm{g})$ \\
\cline { 3 - 3 } & Ag Nanoparticles GMMS leaf extract & $\mathrm{HeLa}$ \\
\hline 1 & & $49.44 \%$ \\
\hline
\end{tabular}

Table-2: Cytotoxic Properties by different conc. of AgNPs on HeLa Cells

\begin{tabular}{|c|c|c|c|c|c|c|c|}
\hline Concentration $(\mu \mathrm{g})$ & \multicolumn{3}{|c|}{ Absorbance at $570 \mathrm{~nm}$} & Average & $\begin{array}{l}\text { Average- } \\
\text { Blank }\end{array}$ & $\begin{array}{c}\% \\
\text { Viability }\end{array}$ & $\mathrm{IC}_{50}(\mu \mathrm{g})$ \\
\hline 100 & 1.101 & 1.103 & 1.105 & 1.103 & 1.1 & 59.363 & \multirow{7}{*}{131.35} \\
\hline 50 & 1.462 & 1.464 & 1.465 & 1.463 & 1.46 & 78.791 & \\
\hline 25 & 1.5 & 1.502 & 1.504 & 1.502 & 1.499 & 80.895 & \\
\hline 10 & 1.588 & 1.59 & 1.592 & 1.59 & 1.587 & 85.644 & \\
\hline 5 & 1.689 & 1.691 & 1.693 & 1.691 & 1.688 & 91.095 & \\
\hline Untreated & 1.856 & 1.857 & 1.856 & 1.856 & 1.853 & 100 & \\
\hline Blank & 0.003 & 0.004 & 0.003 & 0.003 & 0 & 0 & \\
\hline
\end{tabular}


RASĀYAN J. Chem.

Vol. 14 | No. 3 |2031-2039| July - September | 2021

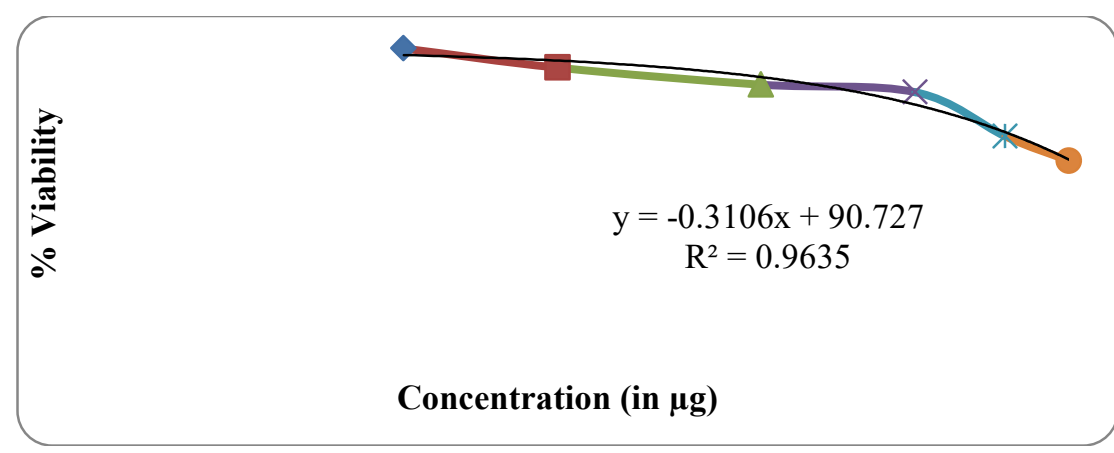

Fig.-8: Cell Viability Test

CONCLUSION

The advantages of using a GMMS plant leaf extract mediated synthesis of Ag nanoparticles include toxicity-free and quick synthesis method without adding any external reagents, economic viability, costeffective and safe in handling large-scale synthesis. AgNPs show effective Antibacterial and anticancer activity. The synthesized biogenic Ag nanoparticles are susceptible to $G+v e$ than $G$-ve bacteria.

\section{ACKNOWLEDGEMENT}

The authors acknowledge heartfelt thanks to Late Dr. T. V. D. Prasad Rao, and my sincere thanks to Dr. Raj Kumar Bandi (Research associate at South Korea), Dr. Bhagavanth Reddy, Dr. Ramakrishna and Dr. Sravanthi kallepali. I acknowledge DST-FIST, New Delhi, India for giving fundamental logical facilities in the Dept. My earnest gratitude to the Dept. of Chemistry, OU, and CFRD-OU, for providing infrastructure and other necessary facilities.

\section{REFERENCES}

1. M. R. Shaik, M. Khan, M. Kuniyil, A. Al-Warthan, H. Z. Alkhathlan, M. R. H. Siddiqui, J. P. Shaik, A. Ahmed, A. Mahmood, M. Khan and S.F. Adil, Sustainability, 10(4), 1(2018), https://doi.org/10.3390/su10040913

2. S. Ahmed, S. Munir, N. Zeb, A. Ullah, B. Khan, J. Ali, M. Bilal, M. Omer, M. Alamzeb, S. M. Salman and S. Ali, International Journal of Nanomedicine, 14(10), 5087(2019), https://doi.org/10.2147/IJN.S200254

3. J. Sheeja, K. Sampath and R. Manivel, Rasayan Journal of Chemistry, 12(1), 262(2019), http://dx.doi.org/10.31788/RJC.2019.1215002

4. D. Garibo, H. A. Borbon-Nunez, J. N. D. de Leon, E. Garcia Mendoza, I. Estrada, Y. ToledanoMagana, H. Tiznado, M. Ovalle-Marroquin, A. G. Soto-Romos, A. Blanco, J.A. Rodriguez, O. A. Romo, L. A. Chavez-Almazan and A. Susarrey-Arce, Scientific Reports, 10, 1(2020), https://doi.org/10.1038/s41598-020-69606-7

5. M. Nakhjavani, V. Nikkhah, M. M. Sarafraz, S. Shoja and M. Sarafraz, Heat and Mass Transfer, 53(10), 3201(2017), https://doi.org/10.1007/s00231-017-2065-9

6. S. Pirtarighat, M. Ghannadnia and S. Baghshahi, Journal of Nanostructure in Chemistry, 9(1), 1(2019), https://doi.org/10.1007/s40097-018-0291-4

7. N. S. Ghosh and R. Singh, Rasayan Journal of Chemistry, 14(1), 486(2021), http://dx.doi.org/10.31788/RJC.2021.1416130

8. R. D. Rivera-Rangel, M. P. Gonzalez-Munoz, M. Avila-Rodriguez, T. A. Razo-Lazcano and C. Solans, Colloids and Surfaces A: A Physicochemical and Engineering Aspects, 536(1), 60(2018), https://doi.org/10.1016/j.colsurfa.2017.07.051

9. D. Arima Selvan, D. Mahendiran, R. Senthil Kumar and A. Kalilur Rahiman, Journal of Photochemistry and Photobiology B: Biology, 180(1), 243(2018), https://doi.org/10.1016/j.jphotobiol.2018.02.014

10. N. Silas and R. S. Lawrence, Rasayan Journal of Chemistry, 13(1), 570(2020), http://dx.doi.org/10.31788/RJC.2020.1315417

11. I. Murali Krishna, G. Bhagavanth Reddy, G. Veerabhadram and A. Madhusudhan, Applied Nanoscience, 6(5), 681(2016), https://doi.org/10.1007/s13204-015-0479-6 
RASĀYAN J. Chem.

Vol. 14 | No. 3 |2031-2039| July - September | 2021

12. R. H. Ahmed and D. E. Mustafa, International Nano Letters, 10(1), 1(2020), https://doi.org/10.1007/s40089-019-00291-9

13. K. Saravanakumar, R. Chelliah, D. Mubarak Ali, D. H. Oh, K. Kathiresan and M.H. Wang, Scientific Reports, 9(1), 5787(2019), https://doi.org/10.1038/s41598-019-42112-1

14. G. Lakshmanan, A. Sathiyaseelan, P. T. Kalaichelvan and K. Murugesan, Karbala International Journal of Modern Science, 4(1), 61(2018), https://doi.org/10.1016/j.kijoms.2017.10.007

15. P. Vijaya Kumar, S. Mary Jelastin Kala and K. S. Prakash, Rasayan Journal of Chemistry, 11(4), 1544(2018), http://dx.doi.org/10.31788/RJC.2018.1144044

16. N. Willian, Syukri, Zulhadjri, A. Labanni and S. Arief, Rasayan Journal of Chemistry, 13(3), 1478(2020), http://dx.doi.org/10.31788/RJC.2020.1335760

17. G. Yaku, B. Rajkumar and T. V. D. Prasad Rao, Asian Journal of Chemistry, 32(2), 458(2020), https://doi.org/10.14233/ajchem.2020.22513

18. S. Iravani, Green Chemistry, 13(10), 2638(2011), https://doi.org/10.1039/C1GC15386B

19. J. M. Joselin, V. Ganesh Kumar, T. Selvaraj, K. Govindaraju and V. Karthick, Rasayan Journal of Chemistry, 13(1), 188(2020), http://dx.doi.org/10.31788/RJC.2020.1315515

20. M. J. Ahmed, G. Murtaza, F. Rashid and J. Iqbal, Journal of Drug Development and Industrial Pharmacy, 45(10), 1682(2019), https://doi.org/10.1080/03639045.2019.1656224

21. A. R. Allafchian, S. Z. Mirahmadi-Zare, S. A. H. Jalali, S. S. Hashemi and M. R. Vahabi, Journal of Nanostructure in Chemistry, 6(2), 129(2016), https://doi.org/10.1007/s40097-016-0187-0

22. M. Gomathi, P. V. Rajkumar, A. Prakasam and K. Ravichandran, Resource-Efficient Technologies, 3(3), 280(2017), https://doi.org/10.1016/j.reffit.2016.12.005

23. A. A. Alfuraydi, S. Devanesan, M. Al-Ansari, M. S. Alsalhi and A. J. Ranjitsingh, Journal of $\begin{array}{llll}\text { Photochemistry and Photobiology Bi } & \text { Biology, 19), }\end{array}$ https://doi.org/10.1016/j.jphotobiol.2019.01.011

24. S. Renjusha and P. H. Vaisakh, Rasayan Journal of Chemistry, 14(3), 165(2021), http://doi.org/10.31788/RJC.2021.1436332

25. M. Khatami, I. Sharifi, M. A. L. Nobre, N. Zafarnia and M. R. Aflatoonian, Green Chemistry Letters and Reviews, 11(2), 125(2018), https://doi.org/10.1080/17518253.2018.1444797

26. R. Sengodan, R. Ranjithkumar, K. Selvam and B. Chandrashekar, Rasayan Journal of Chemistry, 11(1), 63(2018), http://dx.doi.org/10.7324/RJC.2018.1111934

[RJC-6258/2020] 